\title{
Proactive and politically skilled professionals: What is the relationship with affective occupational commitment?
}

\author{
Amna Yousaf • Karin Sanders • Helen Shipton
}

Published online: 4 June 2011

C The Author(s) 2011. This article is published with open access at Springerlink.com

\begin{abstract}
The aim of this study is to extend research on employee affective commitment in three ways: (1) instead of organizational commitment the focus is on occupational commitment; (2) the role of proactive personality on affective occupational commitment is examined; and (3) occupational satisfaction is examined as a mediator and political skills as moderator in the relationship between proactive personality and affective occupational commitment. Two connected studies, one in a hospital located in the private sector and one in a university located in the public sector, are carried out in Pakistan, drawing on a total sample of over 400 employees. The results show that proactive personality is positively related to affective occupational commitment, and that occupational satisfaction partly mediates the relationship between proactive personality and affective occupational commitment. No effect is found for a moderator effect of political skills in the relationship between proactive personality and affective occupational commitment. Political skills however moderate the relationship between proactive personality and affective organizational commitment.
\end{abstract}

\footnotetext{
A. Yousaf $(\bowtie)$

Department of Management Sciences, COMSATS Institute of Information Technology, Islamabad, Pakistan

e-mail: amna.yousaf@comsats.edu.pk

K. Sanders

Organizational Psychology and Human Resource Development, University of Twente, Enschede, the Netherlands

K. Sanders

School of Organisation \& Management, Australian School of Business,

The University of New South Wales, Sydney, Australia

e-mail: k.sanders@gw.utwente.nl

e-mail: k.sanders@unsw.edu.au

H. Shipton

Aston Business School, Birmingham, UK

e-mail: h.shipton@aston.ac.uk
} 
Keywords Affective occupational commitment - Proactive personality - Occupational satisfaction · Political skills · Affective organizational commitment

Affective organizational commitment (ORC) has received considerable attention in the last few decades from scholars across wide disciplines (Cohen, 2003, 2007; Cooper-Hakim \& Viswesvaran, 2005; Morrow, 1993). An abundance of research suggests that affectively committed individuals (Allen \& Meyer, 1990) are more capable of enhancing desirable organization-level outcomes than their less committed counterparts. Indeed, ORC, defined as the employee's emotional attachment to the organization, seems to be a key precursor for many organizationally relevant outcomes such as organizational citizenship behavior, reduced absenteeism, increased organizational effectiveness, and extra role behavior (Cohen, 2003, 2006; Katz \& Kahn, 1978; Steers, 1977). ORC has also been reported to be a stronger predictor of voluntary turnover in comparison with variables like job satisfaction (Mathieu \& Zajac, 1990; Porter, Steers, Mowday, \& Boulian, 1974; Thatcher, Stepina, \& Boyle, 2002-2003).

In addition to the organization, various foci of commitment have been recognized recently (Cohen, 2003). One such focus of commitment is a person's occupation (Blau \& Lunz, 1998; Cohen, 2007). Where occupational commitment has an affective dimension, it may be referred to as an employee's emotional identification with his/her work goals and occupation (Lee, Carswell, \& Allen, 2000; Morrow \& Wirth, 1989; Vandenberg \& Scarpello, 1994: 535). In terms of the outcomes of occupational commitment (OCC), it has been suggested that OCC has a potential link to occupational turnover (see Colarelli, 1998) which can be considered as a loss not only for the organization but for the society at large as well because of the consequences it poses in terms of the "loss of experience" for the whole profession.

Several scholars (e.g., Handy, 1994; Johnson, 1996) have suggested that the focus of attention for commitment research may be shifting from the organization to the occupation. Among the drivers are trends towards globalization, employees dealing with extensive organizational change and uncertainty such as organizational restructurings, increased job insecurity perceptions, and contingency workforce growth (Hall \& Moss, 1998; Nollen \& Axel, 1996). Furthermore, education levels continue to rise, work is becoming more specialized, and people are more concerned about their occupations which represent a meaningful focus in their lives. Given these trends, careers have become increasingly protean and boundaryless, leaving career development increasingly solely the responsibility of the employee him-/herself and removing responsibility from organizational management. In line with these various ideas, in this study we focus on affective OCC, yet take affective ORC into account to make a comparison between the two foci of commitment.

It seems that despite progress, there are still substantial gaps in our understanding of what factors promote commitment, whether defined in organizational or occupational terms. In examining the antecedents of commitment, environmental rather than dispositional sources are typically considered, despite a surge in research looking at the dispositional sources of job attitudes such as job satisfaction (Judge, Heller, \& Mount, 2002). Interestingly, so far only minimal attention has been directed toward understanding the dispositional basis of 
commitment (Erdheim, Wang, \& Zickar, 2006). For instance a few studies have investigated relationships between some aspects of personality and organizational commitment such as affectivity, and the Big Five personality traits such as extraversion and conscientiousness (e.g., Erdheim et al., 2006; Watson, Clark, \& Tellegen, 1984), providing evidence that some individuals may be predisposed to experience heightened or diminished levels of ORC. Although the importance of the Big Five model has been largely acknowledged in the literature, researchers have shown that personality traits such as proactive personality (PP) are differentially associated with the Big Five personality traits and positively predict a number of criterion variables over and above the contribution of the Big Five traits and other relevant predictor variables (Crant, 1995; Crant \& Bateman, 2000). Consequently, the first aim of the current study is to assess the extent to which PP could explain variance in employees' affective OCC. We use the framework of affective event theory (Weiss \& Cropanzano, 1996; see also Li, Ahlstrom, Ashkanasy, 2010) to theorize about this proposed relationship.

A second aim of this study is to identify the possible mechanism that could explain the PP-OCC relationship. Any mechanism that is revealed would shed light on how the proposed relationship might be executed. In doing so, we use the framework of employees' occupational satisfaction since proactive people can be expected to be more satisfied within the broader environment of their occupational networks. Since our study takes place in an Asian cultural setting where the country's prevailing social norms and expectations are quite different from Seibert et al.'s (Seibert, Crant, \& Kraimer, 1999; Seibert, Kraimer, \& Crant, 2001) investigation on PP in US organizations (Ahlstrom, 2010), another contribution of our research is to shed light on factors likely to precipitate commitment in this setting.

More and more attention is paid nowadays to the importance of political skills in professional organizations. Political skills represent the ability "to exercise formal power with sensitivity to the feelings of others, to know where to concentrate one's energies, to sense what is possible, to organize the necessary alliances" (Mintzberg, 1983: 26). A few studies have demonstrated that political skills buffer the negative effects of social stressors on satisfaction. Further, it has been argued that future research should consider political skills as a moderator of other relationships (Harvey, Stoner, Hochwarter, \& Kacmar, 2007; Perrewe et al., 2005). Research suggests that although proactive personality and political skills share some of the same features, they are distinct constructs. This makes it interesting to understand how the two constructs interact with each other in a model and how the predictor-outcomes relationship is moderated by these emerging social effectiveness skills (i.e., political skills). This forms the last research goal of this study.

It is important to note that out of the three dimensions of occupational commitment - affective, normative, and continuance - as conceptualized by Meyer, Allen, and Smith (1993), we chose to study the relationship between PP and the affective dimension of OCC. Secondly, building our theory on parts of affective event theory (Weiss \& Cropanzano, 1996), we expected that since proactive individuals are expected to act in ways that can lead to situations that provoke positive or negative emotions (affect) at work, PP can determine their affective OCC. 


\section{Proactive personality and affective commitment}

People differ in their propensity to take actions to influence their environment. PP has been proposed as a personality trait to explain these differences across individuals (Bateman \& Crant, 1993; Crant, 1995, 2000). PP is seen as an individual characteristic that reflects a person's tendency to be minimally hindered by situational constraints and maximally empowered to take personal initiative to ensure a positive outcome in whatever environment that person occupies (Bateman \& Crant, 1993). From an organization's perspective, PP is a desirable characteristic for employees to possess.

Since its emergence in the early 1990s, PP has gained momentum as a valid construct and a predictor of relevant outcomes, including organizational performance (Crant, 1995), work adjustment (Kammeyer-Mueller \& Wanberg, 2003), the ability to deal with occupational constraints (Parker \& Sprigg, 1999), and leadership performance (Crant \& Bateman, 2000). PP has also been linked with actual advancements in salary and position (Seibert et al., 1999; Seibert et al., 2001), job search success (Brown, Cober, Kane, Levy, \& Shalhoop, 2006), organizational citizenship behavior (Parker, 1998), career success (Seibert et al., 2001), and team effectiveness (Kirkman \& Rosen, 1999).

Weiss and Cropanzano (1996) proposed a framework to explain the structure, causes, and consequences of affective experiences at work. They labeled their framework the affective events theory (AET) and focused on workplace events as proximal causes of affective reactions. Weiss and Cropanzano proposed that features of the work environment set up a structure in which certain active events are more or less likely to take place. Affective experiences in the workplace lead to consequences that are both attitudinal and behavioral (Weiss \& Cropanzano, 1996). Work attitudes are influenced by affective experiences, which in turn influence cognitive judgmentdriven behaviors. Although there is large amount of research on how situational variables, work contexts, and job characteristics influence the work environment that could influence the affective experience of work, we know less about the possible sources of affect, especially those factors relating to personality traits.

We expect that proactive individuals due to their innate abilities to mould work situations in their favor owing to their problem solving skills, generate events that are congruent to the pursuit of their personal goals (Weiss \& Cropanzano, 1996). Proactive people have been shown to engage in active surveying of their environment, maintaining vigilance, and enacting behaviors intended to bring about desired outcomes. Proactive people actively seek out new information and practices in order to improve their performance (Bateman \& Crant, 1993; Crant, 2000). These features are suggestive of the capabilities proactive people have to mould their work situation and environment - in the way they want.

This reasoning suggests that the affective reactions of individuals and the strength of those reactions may depend on how relevant the situation is in connection with the pursuit of personal and professional goals. The emergence of favorable work situations as a result of the proactive efforts of individuals seems likely to lead to the arousal of positive affective states and thus higher affective commitment. This means that any appraisals of benefits could be logically assumed to lead to pleasant affective states. On the other hand, proactive initiative-taking might lead to experiences or situations that are 
contrary to what was expected (or incongruent with their expectations), meaning that PP may not always bring positive consequences. Appraisals of impediments (goal obstruction) may lead to unpleasant affective states (Weiss \& Cropanzano, 1996). Negative feelings that are activated by a failure of initiative-taking (unexpected work situation or event) are likely to reduce commitment.

Whether PP is associated with higher or lower commitment is a question that has so far received limited empirical attention (Chan, 2006; Kohler \& Mathieu, 1993; Vandenberghe, Bentein, \& Stinglhamber, 2004). Indeed, as noted in the beginning, there is overall a lack of research explaining the dispositional basis of commitment. Taken together, the characteristics that proactive people exhibit suggest that they try to improve their current jobs and collect information about existing or possible career opportunities. The above line of reasoning leads us to the following hypothesis:

Hypothesis 1 Proactive personality is positively related to the affective occupational commitment of employees.

\section{Occupational satisfaction as a mediator}

Occupational or career satisfaction refers to a subjective dimension of career success and is defined as the overall affective orientation of the individual toward his or her career or work role (Gattiker \& Larwood, 1988). Extant research uses the terms career, occupation, and profession interchangeably for the same construct (Lee et al., 2000; Morrow, 1993). In this study we chose the term occupational satisfaction because we find it more relevant and keeping with our study, given our focus on occupational commitment.

Proactive individuals tend to actively engage in updating their knowledge and skills and identifying new work processes. Through displaying initiative and surpassing normal occupational expectations, proactive people might be expected to report relatively high satisfaction at work. In addition, proactive people are more likely to identify opportunities and to act on them by exceeding normal occupation expectations (Seibert et al., 2001; Van Dyne \& LePine, 1998). Further, proactive individuals will be more satisfied with their occupation because they will remove obstacles preventing satisfaction (Erdogan \& Bauer, 2005: 861).

Both theoretical and empirical work suggests that higher levels of job satisfaction, defined as the degree to which people like their jobs (Spector, 1997), are associated with higher levels of ORC (Brown \& Peterson, 1993; Curry, Wakefield, Price, \& Mueller, 1986; Matzler \& Renzl, 2007; Meyer, Stanley, Herscovitch, \& Topolnytsky, 2002). Although we could locate few studies examining the relationship between occupational satisfaction and OCC (Lee et al., 2000), we expect that just as job satisfaction is related to ORC, occupational satisfaction would be related to OCC and would thus provide a mediating mechanism in the linkage between PP and OCC. Also, as noted earlier, since actions taken by proactive individuals can also lead to negative events (situations) which can invite negative reactions, satisfaction with organizational and occupational life seems really important to keep the individuals committed. 
Studies show that proactive individuals are purported to "select, create, and influence work situations that increase the likelihood of career success" (Seibert et al., 2001: 847). Not only are proactive individuals likely to take initiative towards making advances in their workplace, but also in their own careers. Career initiative involves a variety of activities including career planning, skill development, and consultation with others (Seibert et al., 2001). Proactive people are thought to possess a greater need for achievement (Thompson, 2005) and a higher motivation to learn (Major, Turner, \& Fletcher, 2006) and thus are expected to be engaged in activities that promote their career prospect. Evidence shows that individuals who reflect more actively about their career goals and who have a stronger insight in what they want to attain during their career, report a higher level of career satisfaction (De Vos, \& Soens, 2008).

Taken together, it could be inferred that proactive people create situations within their occupational environment which are more favorable and satisfying for them leading to their higher attachment with their occupations. The above line of reasoning leads us to the development of the second hypothesis:

Hypothesis 2 The relationship between proactive personality and affective occupational commitment is mediated by occupational satisfaction of employees.

\section{Moderating role of political skills in the PP-employee commitment relationship}

There is a need to understand when PP leads to more positive outcomes (Crant, 2000), and to further contribute to understanding the relationship between PP and employee outcomes, we examine the role of political skills as a potential moderator. It is important to note that where proactivity refers to the dispositional aspect of personality and is more or less stable over time, political skills are not simply trait-based; they can be learned and developed over time (Ferris et al., 2005). These features of the two constructs make them distinct, although they have been reported to share some similar features (Liu, Ferris, Zinko, Perrewe, Weitz, \& Xu, 2007).

It has been argued in the literature that to fit within the political environment of organizations, individuals need not only the will but also the skills to successfully execute political behaviors (Mintzberg, 1983, 1985). Modern day competitive organizations select individuals on the criteria of their networking skills, their capability to attract external funding, professional contacts, and their managerial abilities. Political skill is an interpersonal effectiveness construct that combines social understanding with the ability to adjust behavior to the demands of the situation in ways that appear sincere, inspire trust and support, and effectively influence others (Ferris et al., 2005). Since such social and networking ability are helpful in accumulating ties and building up networks, one who is more politically skillful is more likely to establish good relationships with "significant" others. Politically skilled employees are likely to rely on upward influence techniques such as reasoning, bargaining, assertiveness, appeals to higher authority, coalition building, and/or friendliness (Kipnis \& Schmidt, 1982), depending on the leadership style of the supervisor. For instance, when the supervisor values competence, a 
politically skilled subordinate may influence him/her through reasoning; with a supervisor who values loyalty, coalition building may be emphasized by the subordinate. Politically skilled individuals are adept at developing and using social networks (Ferris et al., 2005). People with good networking abilities have been shown to be more calculating and shrewd about the social connections needed to achieve their goals (Ferris et al., 2005).

Since proactive people are more likely to take initiatives to mould the work situation, in certain events the initiative-taking can go wrong and make the situation less favorable than expected. That is why political skills might enhance the chances of the initiative-taking achieving desirable ends relating to occupations, in turn increasing positive emotions and strengthening affective OCC. We expect that an important social networking characteristic such as political skills might moderate the relationship between PP and employee commitment in that politically skilled individuals are more self-confident, possess larger social networks, and exhibit more interpersonal influence. Furthermore, such individuals are socially astute, and know the precise way to adjust their behavior in order to be interpersonally appropriate and effective (Ferris et al., 2005). They use their knowledge to influence others to act in ways that promote personal and/or organizational goals. Through networking activities and via their ability to be convincing and persuasive, employees with political skills are more likely than others to secure things needed for their occupations. Owing to these features, we propose the following hypotheses:

Hypothesis 3 Political skills strengthen the relationship between proactive personality and the occupational satisfaction of employees.

Hypothesis 4 Political skills strengthen the relationship between proactive personality and the affective occupational commitment of employees.

It is noteworthy that we conducted this research in Pakistan, a non-Western culture. Most of the extant PP and commitment research has been based on US and other Western samples. Although there tends to be a clear distinction between workplace and after-work relationships in the West, in Pakistan this is not necessarily so. Because Pakistan scores highly as a collectivist state (Hofstede, 2001, 2007), informal relationships are given strong weighting than formal working relationships. Therefore, employees tend to mix both realms, and various after-work social activities may strengthen relationships with significant others. Employees who are more politically skillful are thus better able to cultivate both formal (in-work) and informal (after-work) relationships with others. Moreover, the high power distance hierarchical culture in Asian region and countries like Pakistan makes the relevance of political skills more marked compared to the Western world. Individuals who are more politically skillful find it easier to develop friendships and build stronger beneficial alliances and coalitions.

A few studies, though conducted in a Western context, do report how politically skilled individuals show better chances of promotions and salary increments. Such benefits are expected to be stronger in a system where policies are not well developed. Differences in the importance and in the implications of political skills across public and private sector have been reported in the literature (Boyne, 2002). A 
significant body of literature has compared the underlying philosophical and operational differences in both public and private work organizations with entirely different cultures (Balfour \& Wechsler, 1990; Rainey, 1989; Rainey, Backoff \& Levine, 1976). Public organizations are often required to operate with fewer resources while maintaining an acceptable level of productivity. Public sector organizations are more bureaucratic, which means that there is lot of red tape involved. For a single thing to be done it has to be passed through the different heads of departments. So it will go from the president to the vice to subordinates under him and the list is continuous. In this kind of environment where hierarchies are stringent and top down, political skills seems more important. Combined with the view that public sector jobs often have "declining prestige, low pay, and poor working conditions" (Balfour \& Wechsler, 1990: 36), the role of political skills cannot be overlooked. Politically skilled people through their networking abilities, social savvy, and astuteness can perform better under such situations. We contend that politically skilled workers might serve to gain favors, mould situations in their favor by their political abilities thus by increasing the interpersonal trust and networking with significant others. By doing so, employees are more likely to commit themselves to the goals of the organization.

In this study we collected data from a private sector hospital and a public sector university (both in Pakistan). Since the culture at private sector organizations is different relative to the public sector, political skills may not be as important there. Therefore, in this study on an exploratory basis we examine if the (moderating) effect of political skills is stronger within the public than in the private sector.

The research model of our study is shown in Figure 1.

\section{Method}

Sample and procedures

Data were collected from doctors at a large Pakistani hospital located in the private sector and from academic employees at a large Pakistani university located in the

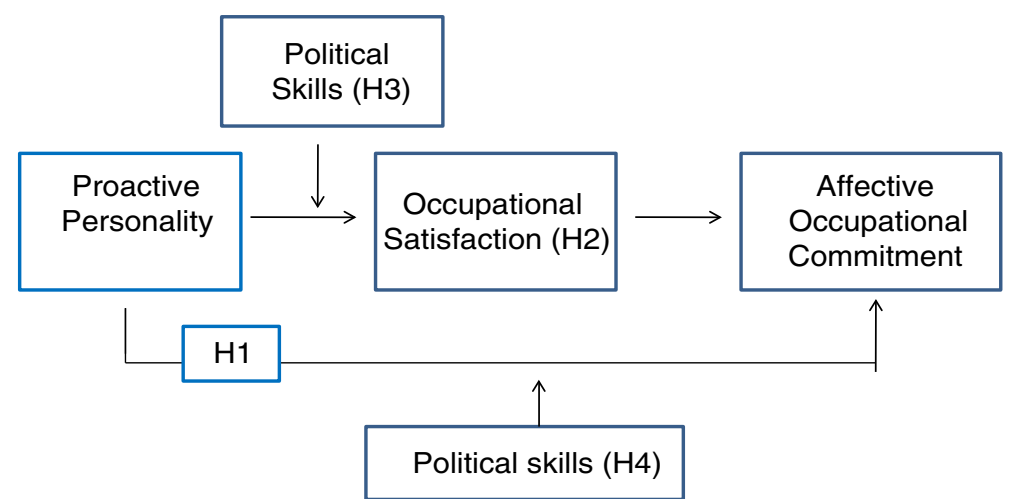

Figure 1 Research model showing relationships between proactive personality and affective occupational commitment 
public sector $(N=411)$. For both the hospital and the university random sampling approach was used. Within the hospital 500 and within the university 750 paper versions of the questionnaire were distributed through interoffice mail in sealed envelopes addressing the employees directly. A reminder mail was sent after 2 weeks so as to solicit a higher response rate. In the hospital 181 of the employees responded making a response rate of $36.2 \%$. The sample was distributed as follows: $54 \%$ of the respondents were males, $49 \%$ was less than 40 years of age, and $52 \%$ had an experience of less than 10 years at the hospital. In the university 230 of the employees responded making a response rate of $31 \%$. The sample was distributed as follows: $56 \%$ of the respondents were males, $46 \%$ was less than 40 years of age, and $49 \%$ had an experience of less than 10 years at the university.

\section{Measures}

A 5-point Likert scale was used to measure the different constructs.

We measured affective occupational commitment using an eight-item scale developed by Meyer et al. (1993). An example item includes "I am proud of my occupation." Alpha reliability for this scale was good (Cronbach's alpha $=.86$ ). As noted in the introduction, in this study we take affective OCC into account to make it possible to compare affective OCC to affective ORC. An eight-item scale developed by Allen and Meyer (1990) was used to measure affective organizational commitment scale with a slight modification of words. An example item includes "I consider the problems of this XXX (name of the hospital, and university, respectively) as my own problems." Alpha reliability for this scale was .82.

A nine-item scale developed by Crant and Kraimer (1999) was used to measure proactive personality. An example item includes "If I see something I don't like, I fix it." Alpha reliability for this scale was .84

A five-item scale developed by Greenhaus, Parasuraman, and Wormley (1990) was used to measure occupational satisfaction. An example item includes "I am satisfied with the progress I have made toward meeting my overall occupational career goals." Alpha reliability for this scale was sufficient (Cronbach's alpha $=.72$ ).

A six-item scale developed by Ferris et al. (1999) was used to measure political skills. An example item includes "I am good at getting others to respond positively to me." Alpha reliability for this scale was sufficient (Cronbach's alpha $=.75)$.

Control variables We used age, gender, and experience as controls as they are generally used in studies of the antecedents and consequences of commitment (e.g., Mathieu \& Zajac, 1990). Controls were coded as follows: males were assigned 1 and females 0 ; employees under 40 years old were assigned 0 while those above 40 were measured by 1 ; employees having less than 10 years experience at the current organization were categorized as 0 and the remaining as 1 . Furthermore we used a dummy to differentiate between the university (0) and the hospital (1) in order to explore the differences between the two sectors. 
Common method variance

Since all data are self-reported and collected through the same questionnaire during the same period of time Harman's one factor test (Podsakoff \& Organ, 1986) was used to investigate the potential influence of common method variance. Results of principal factor analysis, using varimax rotation, did not show that the first (largest) factor accounted for a majority of the variance (26.81\% for the hospital sample and $24.45 \%$ for the university sample), nor was there a general factor that accounted for the majority of the covariance in these variables. The results suggested that common method variance may not be a potential problem for this sample. We also checked the multicollinearity among the independent variables in the regression by examining the variance inflation factor (VIF). The largest VIF value was 2.14, less than the cut-off value of ten (Chatterjee, Hadi, \& Price, 2000) or five (Neter et al., 1990). This result showed that multicollinearity was not a problem in our analyses.

Due to the high correlation between political skills and occupational satisfaction $(r=.71, p<.01$; see Table 1$)$ we conduct a confirmatory factor analysis. We obtained maximum likelihood solutions using MPlus (Muthen \& Muthen, 2009). To be more specific, we compared a two-factor model having two distinct factors with a single-factor model in which all observed indicators are loaded on to one factor. The single-factor model showed low values of Goodness-of-Fit index (GFI) and Adjusted Goodness-of-Fit Index (AGFI) indicating a poor fit of the model with the data (.84 and .71 respectively). The two-factor model based on two distinctive factors, political skills and occupational satisfaction, showed a substantive increase of both GFI and AGFI, to .95 and .92 which are above the normally accepted levels. In addition, the Root Mean Square Residual (RMR) of the two-factor model is .04 which is conventionally regarded as a good fit.

Table 1 Means, standard deviations, and intercorrelations among variables.

\begin{tabular}{lcccccccccc}
\hline Variables & Mean & SD & 1 & 2 & 3 & 4 & 5 & 6 & 7 & 8 \\
\hline 1. Sex $(1=$ male $)$ & 0.47 & .50 & & & & & & & \\
2. Age $(1=>40$ years $)$ & 0.50 & .50 & .04 & & & & & & \\
3. Work experience & 0.46 & .50 & .03 & $.38^{* *}$ & & & & & \\
$\quad(1=>10$ years $)$ & & & & & & & & & & \\
4. Sample $(1=$ hospital $)$ & .44 & .50 & -.03 & -.07 & -.08 & & & & & \\
5. Proactive personality & 3.61 & .55 & $.14^{* *}$ & .06 & -.06 & -.07 & & & \\
6. Political skills & 3.90 & .51 & $.14^{* *}$ & $.13^{* *}$ & $.15^{* *}$ & .03 & $.43^{* *}$ & & \\
7. Occupational satisfaction & 3.80 & .62 & $.12^{*}$ & .10 & $.11^{*}$ & .02 & $.30^{* *}$ & $.71^{* *}$ & \\
8. OCC & 4.18 & .68 & .07 & .05 & $-.10^{*}$ & -.05 & $.52^{* *}$ & $.28^{* *}$ & $.28^{* *}$ \\
9. ORC & 3.04 & .84 & -.02 & $.14 * *$ & .02 & -.07 & $.25^{* *}$ & $.21^{* *}$ & $.28^{* *}$ & $.43^{* *}$ \\
\hline
\end{tabular}

$N=411$

OCC Affective Occupation Commitment; ORC Affective Organizational Commitment.

$* p<.05, * * p<.01$. 


\section{Results}

The means, standard deviations, and interrelations of all the variables are presented in Table 1. Proactivity was significantly related to sex $(r=.14, p<.01)$; male respondents reported more PP than female respondents. Significant relations were found between PP and OCC, $(r=.52, p<.01)$ and between PP and occupational satisfaction $(r=.30, p<.01)$. Moreover occupational satisfaction and OCC were significantly related $(r=.28, p<.01)$. Political skills were related significantly to sex $(r=.14, p<.01)$, to age $(r=.13, p<.01)$, and to experience $(r=.15, p<.01)$, meaning male respondents reported more political skills than female respondents, and older and more experienced respondents reported more political skills than younger and less experienced respondents. Furthermore, political skills were related to OCC $(r=.28, p<.01)$. Proactivity and political skills were found to be related with each other $(r=.43, p<.01)$ as also suggested in previous research (Liu et al., 2007). No differences between the two samples (hospital versus university) and the different constructs were found.

When comparing OCC to ORC, the results showed that organizational commitment (ORC) was related to age $(r=.14, p<.01)$, meaning older respondents reported more commitment to the organization than the younger respondents. ORC was significantly positively related to PP $(r=.25, p<.01)$, to political skills $(r=$ $.21, p<.01)$, and to occupational satisfaction $(r=.28, p<.01)$. It can be noted that these different relationships were stronger for OCC than for ORC. Although ORC and OCC were related to each other $(r=.43, p<.01)$, respondents showed significantly higher commitment to their occupation than to their organization $(M=4.18$ vs. $M=$ $3.04 ; \mathrm{t}(410)=28.07, p<.01)$.

Table 2 reports results of regression analyses done to test the different hypotheses of this study. No significant relationships were found between any of the control variables, sex, age, and experience, and the model outcomes. Same analyses were done without these control variables; results were the same and no other conclusions regarding the (non)confirmation of the hypotheses could be drawn. In Table 2 the results with the control variables taken into account are reported. ${ }^{1}$

To test for mediation hypotheses - following the three steps given by Baron and Kenney (1986) - the mediator (occupational satisfaction) was regressed on the independent variable (PP) as shown in Model 1 of Table 2. Results showed that PP has a positive relationship with occupational satisfaction $(\beta=.30, p<.01)$. Thus, the relationship between the independent variables and the mediator has been established. Second, the dependent variable (OCC) is related to the independent variable (PP) to test H1 (Model 2). Results showed that PP is positively related to OCC $(\beta=.51, p<.01)$. This result confirmed H1.

In Model 3 we tested for the proposed mediation of occupational satisfaction in the PP-OCC relationship. Results showed that the effect of PP was reduced, yet still significant when entering occupational satisfaction in the equation $(\beta=.36, p<.01$

\footnotetext{
${ }^{1}$ Results of the analyses without the control variables, sex, age and experience, can be required by the first author: a.yousaf@gw.utwente.nl.
} 
Table 2 Results of regression analysis showing mediation and moderation model $(N=411)$.

\begin{tabular}{|c|c|c|c|c|c|c|c|c|}
\hline \multicolumn{2}{|c|}{ Variables } & \multirow{2}{*}{$\begin{array}{l}\text { OS } \\
\text { Model } 1\end{array}$} & \multirow{2}{*}{$\begin{array}{l}\text { OCC } \\
(\mathrm{H} 1) \\
\text { Model } 2\end{array}$} & \multirow{2}{*}{$\begin{array}{l}\text { OCC } \\
(\mathrm{H} 2) \\
\text { Model } 3\end{array}$} & \multirow{2}{*}{$\begin{array}{l}\text { OS } \\
(\mathrm{H} 3) \\
\text { Model } 4\end{array}$} & \multirow{2}{*}{$\begin{array}{l}\text { OCC } \\
(\mathrm{H} 4) \\
\text { Model } 5\end{array}$} & \multirow{2}{*}{$\begin{array}{l}\text { OCC } \\
\text { Model } 6\end{array}$} & \multirow{2}{*}{$\begin{array}{l}\text { ORC } \\
\text { Model }\end{array}$} \\
\hline & & & & & & & & \\
\hline & & Mediation & n model & & Moderati & on model & Total & \\
\hline \multirow[t]{4}{*}{ Step 1} & Sex & -.08 & -.01 & .01 & -.02 & .01 & .01 & .05 \\
\hline & Age & .04 & .05 & .05 & .02 & .05 & .05 & .10 \\
\hline & Experience & -.08 & -.10 & -.09 & -.01 & -.09 & -.11 & -.02 \\
\hline & Sample & .04 & -.02 & -.02 & .01 & -.03 & -.03 & -.05 \\
\hline \multirow[t]{4}{*}{ Step 2} & Proactive personality (PP) & $.30 * *$ & $.51 * *$ & $.36 * *$ & .01 & $.48 * *$ & $.35 * *$ & $.25^{* *}$ \\
\hline & Political skills (PS) & & & & $.72 * *$ & $.08^{* * *}$ & $.08 * * *$ & $.17^{* *}$ \\
\hline & Occupational Satisfaction (OS) & & & $.15^{* *}$ & & & $.17 * *$ & $.13^{* *}$ \\
\hline & PS X PP & & & & .02 & -.04 & -.04 & $.14 * *$ \\
\hline \multirow[t]{4}{*}{ Step 3} & PP X Sample & & & & & & -.07 & -.05 \\
\hline & PS X Sample & & & & & & .01 & -.01 \\
\hline & PP x PS X Sample & & & & & & -.02 & -.04 \\
\hline & $R^{2}$ & .11 & .28 & .30 & .49 & .29 & .31 & .15 \\
\hline
\end{tabular}

$N=411$.

OS Occupational Satisfaction; OCC Affective Occupation Commitment; ORC Affective Organizational Commitment.

** $p<.01, * * * p<.10$.

from $\beta=.51, p<.01)$. Occupational satisfaction was significantly related to OCC $(\beta=.15, p<.01)$. These results suggest partial mediation of occupational satisfaction in the PP-OCC relationship. Results of Sobel test also indicated partial mediation of occupational satisfaction in the PP-OCC link $(z=2.68, p<.01)$, thus partially confirming $\mathrm{H} 2$.

To test H3, which related to the moderation of political skills in the PPoccupational satisfaction relationship, we regressed occupational satisfaction on PP, political skills, and the interaction between PP and political skills in Model 4. Results showed that PP was not significantly related to occupational satisfaction but political skills was $(\beta=.01, n s ; \beta=.72, p<.01$, respectively). Model 4 shows that the interaction of PP and political skills was not significantly related to occupational satisfaction $(\beta=.02, n s)$. This means that $\mathrm{H} 3$ could not be confirmed. However, these results suggest a mediating effect of political skills in the relationship between PP and occupational satisfaction as the effect of PP reduced from $.30(p<.01)$ to $.01(n s)$.

In Model 5 we tested $\mathrm{H} 4$ which is related to the moderation of political skills in the relationship between PP and occupational commitment. OCC was regressed on PP, political skills, and the interaction between PP and political skills. Results showed that PP was significantly related to OCC while political skills was only slightly related to $\mathrm{OCC}(\beta=.48, p<.01 ; \beta=.08, p<.10$, respectively). Results showed that political skills did not moderate the relationship between PP and OCC $(\beta=-.04, n s)$. This means that $\mathrm{H} 4$ could not be confirmed. 
In Model 6 we take all variables, and the different interactions into account to explore if the effects of PP and political skills were different for the public and private sector. Furthermore in Model 7 we make a comparison with ORC. For OCC, the different two-way interaction effects (PP X Sample, PS X Sample; $\beta=-.07, n s$; $\beta=.01, n s$, respectively) and the three way interaction (PP X PS X Sample; $\beta=$ $-.02, n s)$ were not significantly related to OCC.

For ORC comparable results for most relationships were found: none of the control variables were found significant, while PP, political skills, and occupational satisfaction were positively related to $\operatorname{ORC}(\beta=.25, p<.10 ; \beta=.17, p<.01 ; \beta=.13$, $p<.01$, respectively). A significant interaction effect of PP and political skills ( $\beta=$ $.14, p<.01$ ) was found for ORC. In order to examine the nature and form of the interactions more closely, we plotted them using procedures by Aiken and West (1991). They are graphically illustrated in Figure 2. This figure shows that political skills strengthen the positive relationship between PP and ORC.

\section{Discussion and conclusions}

In this paper, we examined the impact of an important personality trait-proactive personality (PP) — on employee affective OCC. Most existing models of employee commitment talk in terms of relationships with organizational and situational criterion with a few studying personality traits as predictors. In this study, the intention was to explore potential mechanisms by which the relationship between PP and employee commitment is executed. This led us to study the extent of employees' commitment to their occupations, at the same time examining the role of employee political skills. These, we have suggested, should have a strengthening influence on the effects of PP on employee commitment directly and/or indirectly through occupational satisfaction.

The study findings generally supported our first hypothesis since PP was positively related to OCC. This suggests that employees with a PP can manipulate their environment in desirable ways and feel better control over their occupational

Figure 2 Moderating role of political skills in the proactive personality and affective organizational commitment relationship

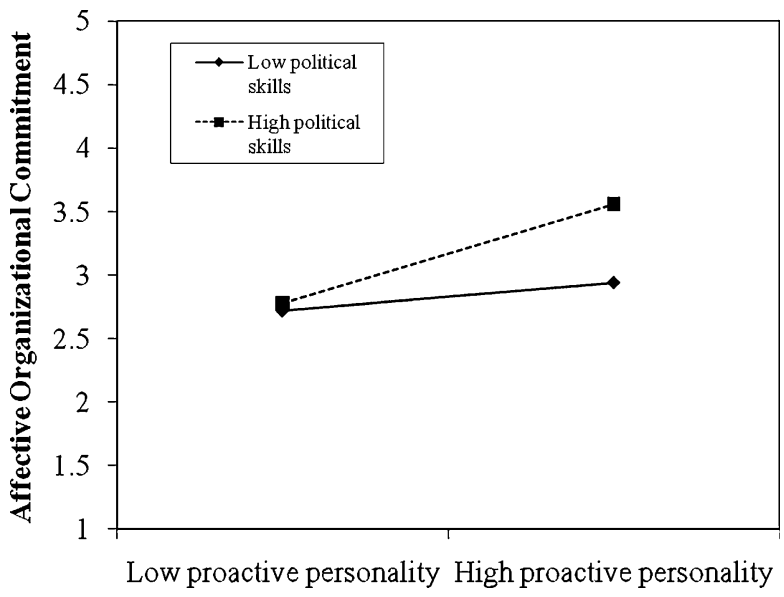


environments. This leads to feelings of emotional attachment and being at home and more comfortable with their occupation. Research has shown that dispositions influence the way in which employees perceive their occupation, which consequently affects their occupational satisfaction (Bowling, Beehr, Wagner, \& Libkuman, 2005) and ultimately translating into higher OCC. This finding extends current employee-organizational relationships literature (Masterson, Lewis, Goldman, \& Taylor, 2000; Settoon, Bennett, \& Liden, 1996). Commitment models thus need to include personality traits also in addition to post employment experiences, and organizational and situational variables as their antecedents.

In $\mathrm{H} 2$, we expected that occupational satisfaction would provide a mediating link in the relationship between PP and OCC. This hypothesis was partially supported in this study. The results extend knowledge in the PP literature by identifying occupational satisfaction as a mediating mechanism. These results have received little, if any, attention in extant research. In H3 we expected political skills to moderate the PP-occupational satisfaction relationship. This hypothesis could not be confirmed. Nor could we confirm (H4) that political skills moderated the direct relationship between PP and OCC. However, we found a strong mediating effect of political skills in the PP and occupational satisfaction relationship.

When these results are compared with the results regressing ORC, similarities and differences can be observed. In terms of similarities, for both OCC and ORC controls did not reveal any significant relationship with the two foci of affective commitment. PP was significantly positively related to both OCC and ORC, yet more strongly related to OCC than to ORC. While political skills were only moderately $(p<.10)$ related to OCC, they were significantly related to ORC: the more politically skilled, the more employees are committed to the organization. Furthermore, political skills moderated the relationship between PP and ORC. This means that ORC of employees who are more proactive and are more politically skilled is greater than the employees whose political skills are not so strong but are proactive. This moderating role of political skills in the PP-ORC relationship could be explained using Ferris et al.'s $(1999,2005)$ conceptualization of political skills as an interpersonal construct. Employees with more political skills are in greater demand for pro-social activities than their moderately skilled counterparts. This means that such employees "put forth extra effort on the job" (Brief \& Motowidlo, 1986: 715).

As noted earlier, political skills did not moderate the PP-OCC relationship which might suggest that political skills refers to interpersonal relationships that are more relevant to an individual's job surroundings (i.e., with his colleagues, supervisors, and other acting bodies within the organization). Put another way, since political skills are more related to the ability of an individual to understand others at the workplace, the construct seems to be more relevant for the ORC than for the OCC of employees. In other words: political skills seem to have less meaning for commitment where the organization is not the focus. However, political skills mediated the relationship between PP and occupational satisfaction, suggesting that PP enhances political skills of employees, and political skills enhance their occupational satisfaction. On the whole, the conclusions of the present study provide evidence that the relationship between PP and employee outcomes is neither simple nor direct (Thompson, 2005). 


\section{Implications}

This study provides an attempt to delineate the mechanism through which PP affects employee commitment. The take-home message is to understand the different variants involved in predicting employee commitment-which is a source of competitive advantage. This study is thus expected to produce a guide for the practitioners and management of organizations, about how employees differ in respect of capabilities such as PP and political skills, and how such individual differences lead to diverse attitudinal outcomes. Organizations might increase their propensity for competitive success if they attract people who have proactive personalities while at the same time are more adept in interpersonal skills such as political skills. Organizations might consider reviewing selection procedures with an eye toward identifying and hiring more proactive employees. Thus, this study implies that there is value in providing space and opportunity for employees to act proactively in the workplace. Given that PP was related to OCC and to ORC and that these relationship were further influenced by political skills of employees, the employees' ability to behave in a proactive and politically skillful way appears to constitute an organizational asset. As noted before, where PP is a relatively stable personality trait, political skills and can be learned and developed so organizational management might facilitate employee learning in ways that contribute to development of their political skills. For instance, organizations may think of assigning skilled mentors and provide other developmental experiences to their employees, which can result in their better political abilities and can ultimately create positive change by influencing important attitudes and behaviors.

\section{Strengths}

This research employed two samples and results provided convergent support for the positive relationship between PP and affective OCC. One sample constituted the doctors at a private sector hospital and the other sample constituted academic staff of a public sector university. The pattern of results was consistent for both samples; thus the results provided some initial evidence of generalizability and demand additional research. This research contributes to the literature by examining the so far untested link between PP and OCC (and ORC) and examining the possible mediator and moderator of occupational satisfaction and political skills.

As was mentioned in the introduction, we conducted this research in the context of a non-Western culture. Most of the PP and commitment research has been based on US and other Western samples. This means that one important contribution of our research was to show that $\mathrm{PP}$ is associated with desirable processes and outcomes in a non-Western culture. Because of the prevalence of small and family owned business in Asia, human resource management (HRM) is generally informal and unsophisticated (Lawler \& Atmiyanandana, 1995). Large firms are more likely to conduct HRM. This further highlights the benefits politically skilled individuals can draw from the organizations where there is no formal HRM. A few studies, though conducted in the Western context, do report how politically skilled individuals show better chances of promotions and salary increments. Such benefits are expected to be stronger in a system where policies are not well developed. On the other hand, building good quality informal relationships is not entirely irrelevant in Western firms despite the 
difference between Western relationships and the Pakistani context. Perhaps this study may provoke more thought about the distinction between effects of political skills across the two entirely different cultures and provide suggestions for future research.

\section{Limitations and research perspective}

The results of this study are synonymic to its limitations. This study, like most studies of PP (Crant, 1995; Crant \& Bateman, 2000; Seibert et al., 1999, 2001), relies on self-reported indicators of constructs by employees who volunteered to participate. Although Herman's one factor test did not support existence of self report bias for both samples, the possibility of such bias cannot be completely ruled out and calls for future research that removes this limitation by means of multi actor data or marker variable approach. Future research should examine other variables that might mediate and/or moderate the relationship between PP and individual outcomes. It is also important to mention that this study was conducted in a Pakistani context where HR policies and practices are not much formalized and therefore the importance of political skills as a socially effective ability may be stronger in day to day dealings and working environments of organizations. It would be interesting to replicate this study by comparing data across cultures, for example the US and European countries, to check for robustness of the conceptual model presented here. It would also be interesting to replicate this study in China. China is well known for its holistic culture (Ji, Peng, \& Nisbett, 2000; see also Law, Wang, \& Hui, 2010). Given this holistic culture, it can be that employees differentiate less between occupational and organizational commitment, as they are both work related, than in less holistic cultures. Furthermore the different countries could be examined from the perspective of the Hofstede "paradigm" (Fang, 2010; Hofstede, 2001, 2007) in which the complex phenomenon of culture is changed in simple and measurable terms.

Finally, a natural extension of this study would be to expand the model and include other dispositions such as the Big Five factor model and determine whether they add incremental variance beyond those included in the present study.

Open Access This article is distributed under the terms of the Creative Commons Attribution Noncommercial License which permits any noncommercial use, distribution, and reproduction in any medium, provided the original author(s) and source are credited.

\section{References}

Ahlstrom, D. 2010. Publishing in the Asia Pacific journal of management. Asia Pacific Journal of Management, 27(1): 1-8.

Aiken, L. S., \& West, S. G. 1991. Multiple regression: Testing and interpreting interactions. Newbury Park, CA: Sage.

Allen, N. J., \& Meyer, J. P. 1990. The measurement and antecedents of affective, continuance, and normative commitment to the organization. Journal of Occupational Psychology, 63: 1-18.

Balfour, D. L., \& Wechsler, B. 1990. Organizational commitment: Antecedents and outcomes in public organizations. Public Productivity \& Management Review, 19(3): 256-277. 
Baron, R. M., \& Kenny, D. A. 1986. The moderator-mediator variable distinction in social psychological research: conceptual, strategic and statistical considerations. Journal of Personality and Social Psychology, 51: 1173-1182.

Bateman, T. S., \& Crant, J. M. 1993. The proactive component of organizational behavior: A measure and correlates. Journal of Organizational Behavior, 14: 103-118.

Blau, G., \& Lunz, M. 1998. Testing the incremental effect of professional commitment on intent to leave one's profession beyond the effects of external, personal, and work-related variables. Journal of Vocational Behavior, 52: 260-269.

Bowling, N. A., Beehr, T. A., Wagner, S. H., \& Libkuman, T. M. 2005. Adaptation level theory, opponent process theory and dispositions: An integrated approach to the stability of job satisfaction. The Journal of Applied Psychology, 90: 1044-1053.

Boyne, G. A. 2002. Public and private management: What's the difference?. Journal of Management Studies, 39(1): 97-122.

Brief, A. P., \& Motowidlo, S. J. 1986. Prosocial organizational behaviors. Academy of Management Review, 11: 710-725.

Brown, S. P., \& Peterson, R. A. 1993. Antecedents and consequences of salesperson job satisfaction: meta-analysis and assessment of causal effects. Journal of Marketing Research, 30: 63-77.

Brown, D., Cober, R., Kane, K., Levy, P., \& Shalhoop, J. 2006. Proactive personality and the successful job search: A field investigation with college graduates. The Journal of Applied Psychology, 91: 717-726.

Chan, D. 2006. Interactive effects of situational judgment effectiveness and proactive personality on work perceptions and work outcomes. The Journal of Applied Psychology, 91: 475-481.

Chatterjee, S., Hadi, A. S., \& Price, B. 2000. Regression analysis by example. New York: John Wiley and Sons.

Cohen, A. 2003. Multiple commitments in the workplace: An integrative approach. Mahwah, NJ: Lawrence Erlbaum Associates.

Cohen, A. 2006. The relationship between multiple commitments and organizational citizenship behavior in Arab and Jewish culture. Journal of Vocational Behavior, 69: 105-118.

Cohen, A. 2007. Commitment before and after: An evaluation and re conceptualization of organizational commitment. Human Resource Management Review, 17: 336-354.

Colarelli, S. M. 1998. Psychological interventions in organizations. An evolutionary perspective. American Psychologist, 53: 1044-1056.

Cooper-Hakim, A., \& Viswesvaran, C. 2005. The construct of work commitment: Testing an integrative framework. Psychological Bulletin, 131: 241-259.

Crant, J. M. 1995. The proactive personality scale and objective job performance among real estate agents. The Journal of Applied Psychology, 80: 532-537.

Crant, J. M. 2000. Proactive behavior in organizations. Journal of Management, 26: 435-462.

Crant, J. M., \& Bateman, T. S. 2000. Charismatic leadership viewed from above: The impact of proactive personality. Journal of Organizational Behavior, 21: 63-75.

Crant, J. M., \& Kraimer, S. E. 1999. Research reports: Proactive personality and career success. The Journal of Applied Psychology, 84: 416-427.

Curry, J. P., Wakefield, D. J., Price, J. L., \& Mueller, C. W. 1986. On the causal ordering of job satisfaction and organizational commitment. Academy of Management Journal, 29: 847-858.

De Vos, A., \& Soens, N. 2008. Protean attitude and career success: The mediating role of selfmanagement. Journal of Vocational Behavior, 73: 449-456.

Erdheim, J., Wang, M., \& Zickar, M. J. 2006. Linking the big five personality constructs to organizational commitment. Personality and Individual Differences, 41: 959-970.

Erdogan, B., \& Bauer, T. N. 2005. Enhancing career benefits of employee proactive personality: The role of fit with jobs and organizations. Personnel Psychology, 58: 859-891.

Fang, T. 2010. Asian management research needs more self-confidence: Reflection on Hofstede (2007) and beyond. Asia Pacific Journal of Management, 27(1): 155-170.

Ferris, G. R., Berkson, H. M., Kaplan, D. M., Gilmore, D. C., Buckley, M. R., Hochwarter, W. A., \& Witt, L. A. 1999. Development and initial validation of the political skill inventory. Paper presented at the Academy of Management, 59th Annual National Meeting, Chicago.

Ferris, G. R., Treadway, D. C., Kolodinsky, R. W., Hochwarter, W. A., Kacmar, C. J., Douglas, C., \& Frink, D. D. 2005. Development and validation of the political skill inventory. Journal of Management, 31: 126-152.

Gattiker, U. E., \& Larwood, L. 1988. Predictors for managers' career mobility, success, and satisfaction. Human Relations, 41: 569-591.

Greenhaus, J. H., Parasuraman, S., \& Wormley, W. M. 1990. Effects of race on organizational experiences, job performance evaluations, and career outcomes. Academy of Management Journal, 33: 64-86. 
Hall, D., \& Moss, J. 1998. The new protean construct: Helping organizations/employees adapt. Organizational Dynamics, 26: 22-37.

Handy, C. 1994. The age of paradox. Boston: Harvard Business School Press.

Harvey, P., Stoner, J., Hochwarter, W., \& Kacmar, C. 2007. Coping with abusive supervision: The neutralizing effects of ingratiation and positive affect on negative employee outcomes. Leadership Quarterly, 18: 264-280.

Hofstede, G. 2001. Culture's consequences: Comparing values, behaviors, institutions, and organizations across nations, 2nd ed. Thousand Oaks, CA: Sage.

Hofstede, G. 2007. Asian management in the 21st century. Asia Pacific Journal of Management, 24(4): 411-420.

Ji, L., Peng, K., \& Nisbett, R. 2000. Culture control and perception of relationships in the environment. Journal of Personality and Social Psychology, 78: 943-955.

Johnson, R. 1996. Antecedents and outcomes of corporate refocusing. Journal of Management, 22: 439-483.

Judge, T. A., Heller, D., \& Mount, M. K. 2002. Five-Factor model of personality and job satisfaction: A meta analysis. The Journal of Applied Psychology, 87: 530-541.

Kammeyer-Mueller, J. D., \& Wanberg, C. R. 2003. Unwrapping the organizational entry process: Disentangling multiple antecedents and their pathways to adjustment. The Journal of Applied Psychology, 88: 779-794.

Katz, D., \& Kahn, R. 1978. The social psychology of organizations, 2nd ed. New York: Wiley.

Kipnis, D., \& Schmidt, S. M. 1982. Profile of organizational influence strategies (Form M). San Diego, CA: University Associates.

Kirkman, B. L., \& Rosen, B. 1999. Beyond self-management: Antecedents and consequences of team empowerment. Academy of Management Journal, 42: 58-74.

Kohler, S. S., \& Mathieu, J. E. 1993. Individual characteristics, work perceptions, and affective reactions influences on differentiated absence criteria. Journal of Organizational Behavior, 14: 515-530.

Law, K. S., Wang, H., \& Hui, C. 2010. Currencies of exchange and global LMX: How they affect employee task performance and extra-role performance. Asia Pacific Journal of Management, 27(4): 625-646.

Lawler, J. J. \& Atmiyanandana, V. 1995. Human Resource Management in Thailand. In LF Moore and PD Jennings (eds.).

Lee, K., Carswell, J. J., \& Allen, N. J. 2000. A meta-analytic review of occupational commitment: Relations with person and work related variables. The Journal of Applied Psychology, 85: 799-811.

Li, Y., Ahlstrom, D., \& Ashkanasy, N. M. 2010. A multilevel model of affect and organizational commitment. Asia Pacific Journal of Management, 27(2): 193-213.

Liu, Y., Ferris, G. R., Zinko, R., Perrewe, P. L., Weitz, B., \& Xu, J. (2007). Predictors and outcomes of political skill and reputation in organizations: A four-study investigation with convergence. Journal of Vocational Behavior, 71: 146-165.

Major, D. A., Turner, J. E., \& Fletcher, T. D. 2006. Linking proactive personality and the big five to motivation to learn and development activity. The Journal of Applied Psychology, 91: 927-935.

Masterson, S. S., Lewis, K., Goldman, B. M., \& Taylor, M. S. (2000). Integrating justice and social exchange: The differing effects of fair procedures and treatment on work relationships. Academy of Management Journal, 43: 738-748.

Mathieu, J. E., \& Zajac, D. M. 1990. A Review and meta-analysis of the antecedents, correlates, and consequences of organizational commitment. Psychological Bulletin, 108: 171-194.

Matzler, K., \& Renzl, B. 2007. Personality traits, employee satisfaction and affective commitment. Total Quality Management, 18: 589-598.

Meyer, J. P., Allen, N. J., \& Smith, C. A. 1993. Commitment to organizations and occupations: Extension and test of a three-component conceptualization. The Journal of Applied Psychology, 78: 538-551.

Meyer, J. P., Stanley, D. J., Herscovitch, L., \& Topolnytsky, L. 2002. Affective, continuance, and normative commitment to the organization: A meta-analysis of interrelations and outcomes. Journal of Vocational Behavior, 61: 20-52.

Mintzberg, H. 1983. Power in and around organizations. Englewood Cliffs, NJ: Prentice-Hall.

Mintzberg, H. 1985. The organization as political arena. Journal of Management Studies, 22: 133-154.

Morrow, P. C. 1993. The theory and measurement of work commitment. Greenwich, CT: Jai Press Inc.

Morrow, P., \& Wirth, R. 1989. Work commitment among salaried professionals. Journal of Vocational Behavior, 34: 40-56.

Muthen, L. K., \& Muthen, B. 2009. Mplus. www.statmodel.com.

Netter, J., Wasserman, W., \& Kunter, M. H. 1990. Applied linear statistics models. Homewood, IL: Irwin.

Nollen, S., \& Axel, H. 1996. Managing contingent workers. New York: American Management Association. 
Parker, S. K. 1998. Enhancing role breadth self-efficacy: The roles of job enrichment and other organizational interventions. The Journal of Applied Psychology, 83: 835-852.

Parker, S. K., \& Sprigg, C. A. 1999. Minimizing strain and maximizing learning: the role of job demands, job control, and proactive personality. The Journal of Applied Psychology, 84: 925-939.

Perrewe, P. L., Zellars, K. L., Rossi, A. M., Ferris, G. R., Kacmar, C. J., Liu, Y., Zinko, R., \& Hochwarter, W. A. 2005. Political skill: An antidote in the role overload-strain relationship. Journal of Occupational Health Psychology, 10: 239-250.

Podsakoff, P. M., \& Organ, D. 1986. Self-reports in organizational research: Problems and prospects. Journal of Management, 12: 531-544.

Porter, L. W., Steers, R. M., Mowday, R. I., \& Boulian, P. V. 1974. Organizational commitment, job satisfaction and turnover among psychiatric technicians. The Journal of Applied Psychology, 59: 603-609.

Rainey, R. C. T. 1989. A new equation for calculating wave loads on offshore structures. Journal of Fluid Mechanics, 204: 295-324.

Rainey, Hal G., Backoff, Robert W. \& Levine, C. H. 1976. Comparing public and private organizations. Public Administration Review, 36: 233-246.

Seibert, S. E., Crant, J. M., \& Kraimer, M. L. 1999. Proactive personality and career success. The Journal of Applied Psychology, 84: 416-427.

Seibert, S. E., Kraimer, M. L., \& Crant, J. M. 2001. What do proactive people do? A longitudinal model linking proactive personality and career success. Personnel Psychology, 54: 845-874.

Settoon, R. P., Bennett, N., \& Liden, R. C. 1996. Social exchange in organizations: Perceived organizational support, leader-member exchange, and employee reciprocity. The Journal of Applied Psychology, 81: 219-227.

Spector, P. 1997. Job satisfaction: Application, assessment, causes and consequences. Thousand Oaks, CA: Sage.

Steers, R. M. 1977. Antecedents and outcomes of organizational commitment. Administrative Science Quarterly, 22: 46-56.

Thatcher, J. B., Stepina, L. P., \& Boyle, R. J. 2002-2003. Turnover of information technology workers: Examining empirically the influence of attitudes, job characteristics, and external markets. Journal of Management Information Systems, 19: 231-261.

Thompson, J. A. 2005. Proactive personality and job performance: A social capital perspective. The Journal of Applied Psychology, 90: 1011-1017.

Van Dyne, L., \& LePine, J. 1998. Helping and voice extra-role behavior: Evidence of construct and predictive validity. Academy of Management Journal, 41: 108-119.

Vandenberg, R. J., \& Scarpello, V. 1994. A longitudinal assessment of the determinant relationship between employee commitments to the occupation and the organization. Journal of Organizational Behavior, 15: 535-547.

Vandenberghe, C., Bentein, K., \& Stinglhamber, F. 2004. Affective commitment to the organization, supervisor, and workgroup: Antecedents and outcomes. Journal of Vocational Behavior, 64: 47-71.

Watson, D., Clark, L. A., \& Tellegen, A. 1984. Cross-cultural convergence in the structure of mood: A Japanese replication and a comparison with US findings. Journal of Personality and Social Psychology, 47: 127-144.

Weiss, H. M., \& Cropanzano, R. 1996. Affective events theory: A theoretical discussion of the structure, causes and consequences of affective experiences at work. Research in Organizational Behavior, 18: $1-74$.

Amna Yousaf ( $\mathrm{PhD}$, University of Twente, the Netherlands) is Assistant Professor, Department of Management Sciences at COMSATS Institute of Information Technology, Islamabad, Pakistan. Her research interests include but are not limited to organizational and occupational commitment, high performance work systems, employee personality traits, employability and LMX relationships". She has been a management banker in the past.

Karin Sanders (PhD, University of Groningen, the Netherlands) is professor of organizational psychology at the University of Twente, the Netherlands and professor of organizational behavior and HRM at the School of Organisation \& Management, Australian School of Business, UNSW, Sydney, Australia. Her research interests are in the field of the effectiveness of human resource management practices and policies and in the field of employees' affective organizational commitment. She has 
published more than 50 articles in peer reviewed psychology and (human resource) management journals like International Journal of HRM, Journal of Vocational Behavior, Organization Studies, Group \& Organization Management, and Small Group Research.

Helen Shipton ( $\mathrm{PhD}$, Aston Business School) is a senior lecturer in HRM/work psychology. Her research interests center on HRM and learning, and she is interested in understanding how organizations achieve the creativity and innovation needed to deal with change. Helen is co-director of the Aston Centre of Human Resources, co-track chair for the British Academy of Management HRM Special Interest Group, and has published extensively in leading journals, including the International Journal of Management Reviews, Applied Psychology-An International Review, and Human Resource Management Journal. 